\title{
Políticas de desenvolvimento territorial no Brasil: o caso do Vale do Ribeira (SP) ${ }^{1}$
}

\author{
Joaquim Alves da Silva Jr. \\ Universidade de São Paulo / Instituto de Energia de Ambiente, Programa de Pós-Graduação \\ em Ciência Ambiental \\ São Paulo / SP - Brasil
}

\begin{abstract}
Este artigo identificou os desafios e as perspectivas do Programa Nacional de Desenvolvimento Sustentável dos Territórios Rurais e do Programa Territórios da Cidadania, utilizando o método do estudo de caso no Vale do Ribeira. Inicialmente houve o fortalecimento de entidades locais da sociedade civil por meio da mobilização e da elaboração participativa do plano territorial. Num segundo momento, a articulação entre os atores sociais e governamentais não ocorreu, refletindo a fragilidade da estrutura institucional das políticas territoriais. O quadro é reforçado no cenário nacional pela perda da relevância da abordagem territorial do desenvolvimento na agenda governamental.
\end{abstract}

Palavras-chave: desenvolvimento rural; abordagem territorial; políticas públicas; sustentabilidade; Vale do Ribeira.

Políticas de desarrollo territorial en el Brazil: el caso del Valle del Ribeira (SP)

Este artículo identificó los desafios y perspectivas del Programa Nacional para el Desarrollo Sostenible dos Territórios Rurales y el Programa Territórios de Ciudadanía, utilizando el método de estudio de caso en el Valle del Ribeira. Al principio hubo el fortalecimento de la organizaciones locales de la sociedade civil, mediante la movilización y la elaboración participativa del plan territorial. En segundo lugar, la articulación entre los actores sociales y gubernamentales no ocurrió, lo que refleja la debilidade de la estructura institucional de las políticas territoriales. El cuadro está reforzado en la escena nacional por la perdida de relevância del enfoque territorial del desarrollo en la agenda del gobierno.

Palabras clave: desarrollo rural; enfoque territorial; políticas públicas, sostenibilidad; Valle del Ribeira.

DOI: http://dx.doi.org/10.1590/0034-7612150613

(c) (1)

Artigo recebido em 8 jun. 2015 e aceito em 1 fev. 2016.

${ }^{1}$ Síntese da dissertação de mestrado defendida em abril de 2015. Agradeço aos revisores pelas valiosas orientações e críticas, a Alexandre Antunes Ribeiro Filho, Jordano Roma Buzati e Melina de Souza Leite pelo apoio nas revisões e ao Laboratório de Ecologia Humana (Lech/IEE/USP), especialmente a Cristina Adams e Daniela Ianovali. Entretanto, sou o único responsável pelo conteúdo do artigo. A pesquisa foi financiada pelo Programa de Demanda Social da Coordenação de Aperfeiçoamento de Pessoal de Nível Superior (DS/Capes). 
Territorial development policies in Brazil: the Ribeira Valley case (SP)

This article seeks to identify the challenges and the prospects of the Nacional Program for Sustainable Development of Rural Territories and of the Citizenship Territories Program, using a case study method of research in the Ribeira Valley. Initially there was a strengthening of local civil society organizations through the mobilization and participatory elaboration of the territorial plan. In the next stage, however, the relationship between social and government actors failed to materialize, reflecting the fragility of the institutional structure of these territorial policies. The scenario is repeated on a national scale, due to the loss of relevance that the territorial development approach has had within the government agenda.

Keywords: rural development; territorial approach; public policies, sustainability, Ribeira Valley.

\section{Introdução}

A releitura crítica da visão agrária do campo denominada por "nova ruralidade" lança luz às dimensões referentes à reaproximação entre os sistemas sociais e ecológicos, à relação de continuum entre o rural e o urbano e à configuração social determinada pela baixa densidade e heterogeneidade populacional (Vieira, 2009; Wanderley, 2000). Tal abordagem convergiu com experiências regionalizadas de desenvolvimento, a exemplo do Programa Leader e dos Contratos Territoriais de Estabelecimento (Beduschi Filho e Abramovay, 2004; Bonnal e Maluf, 2009; Sabourin, 2012). O enfoque no território enfatiza o capital social e as inovações localizadas como fatores estruturais de dinamização socioeconômica e de promoção da sustentabilidade no meio rural (Abramovay, Magalhães e Schroder, 2010). Nas últimas duas décadas, a abordagem territorial difundiu-se na América Latina, em especial no Brasil, consolidando um referencial de mobilização para os movimentos da agricultura familiar, de promoção da ação coletiva e de regulação de políticas diferenciadas para o meio rural (Delgado e Grisa, 2014; Favareto, 2010; Grisa e Schneider, 2014; Karam, 2012; Sabourin, 2015; Sant'Anna Porto, 2015; Zimmermann et al., 2014).

A emergência da abordagem territorial foi concomitante à profunda reestruturação do Estado brasileiro, decorrida da Constituição Federal de 1988. As críticas direcionadas à centralidade da atuação estatal foram respondidas com a reforma gerencial, prevista segundo as diretrizes neoliberais de redução do Estado, que por outro lado fortaleceu os mecanismos de accountability horizontal e incluiu o princípio da eficiência na administração pública (Paula, 2005). Na outra ponta, a gestão pública materializou o conceito de esfera pública e o princípio da descentralização ao instituir estruturas participativas de inclusão da pluralidade dos interesses e da diversidade dos atores, ao estimular a coprodução do bem público (Ribeiro, Andion e Burigo, 2015), ao promover a atuação do Estado em rede (Goulart et al., 2010) e ao criar os mecanismos de controle social, ou de accountability vertical (Gurza Lavalle e Isunza, 2011), atributos estes relacionados com abordagem social da gestão (Zani e Tenório, 2014). Esta última, por sua vez, se liga ao ciclo de gestão (policy cycle), o qual olha para a complexidade temporal da ação pública e converge com o campo da policy analysis (Frey, 2000), que 
inter-relaciona a análise da estrutura institucional (polity), dos processos de negociação e conflito (politics) e dos conteúdos da política pública (policy) (figura 1).

Figura 1

Simplificação das proposições teórico-metodológicas

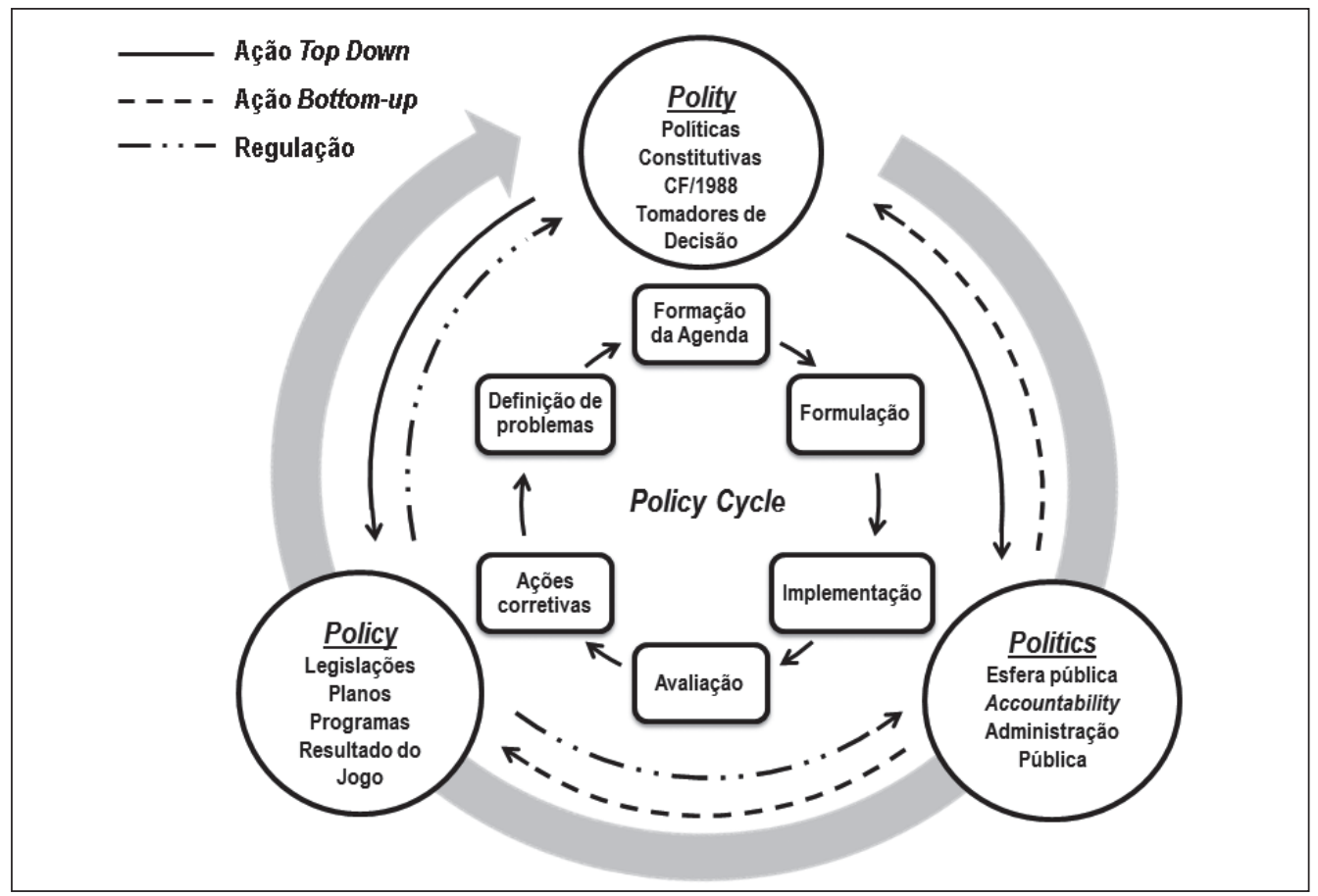

Fonte: Elaborada a partir de Frey (2000), Goulart e colaboradores (2010), Gurza Lavalle e Isunza (2011) e Paula (2005).

A entrada dos anos 2000 marca a emergência das novas institucionalidades territoriais. Em 2003, o Programa Nacional de Desenvolvimento Sustentável dos Territórios Rurais (Pronat) é implantado sob a coordenação da Secretaria de Desenvolvimento Territorial do Ministério do Desenvolvimento Agrário (SDT/MDA). O Pronat visa à concertação participativa de uma estratégia de desenvolvimento rural fundamentada no marco territorial da política e na integração horizontal e vertical dos atores e instituições (figura 2). Em 2008, surge o Programa Territórios da Cidadania (PTC) sob a coordenação do Ministério da Casa Civil (MCC), com o objetivo inovador de integrar o enfoque territorial à proposta de universalização das políticas sociais e da intersetorialidade das ações, cujo objetivo é o desenvolvimento rural sustentável (Aquino e Silva, 2015; Caldas e Moreira, 2013; Carvalho e David, 2011; Favareto e Schroder, 2007; Freitas, Freitas e Dias, 2012; Oliveira et al., 2014; Souza e Amaral, 2015). Porém, ressalta-se que, após uma década de implementação, são inúmeros os desafios para a real efetividade das políticas anteriormente descritas (Berdegué, Escobal e Bebbington, 2015). 
Figura 2

Ciclo de gestão das políticas de desenvolvimento territorial

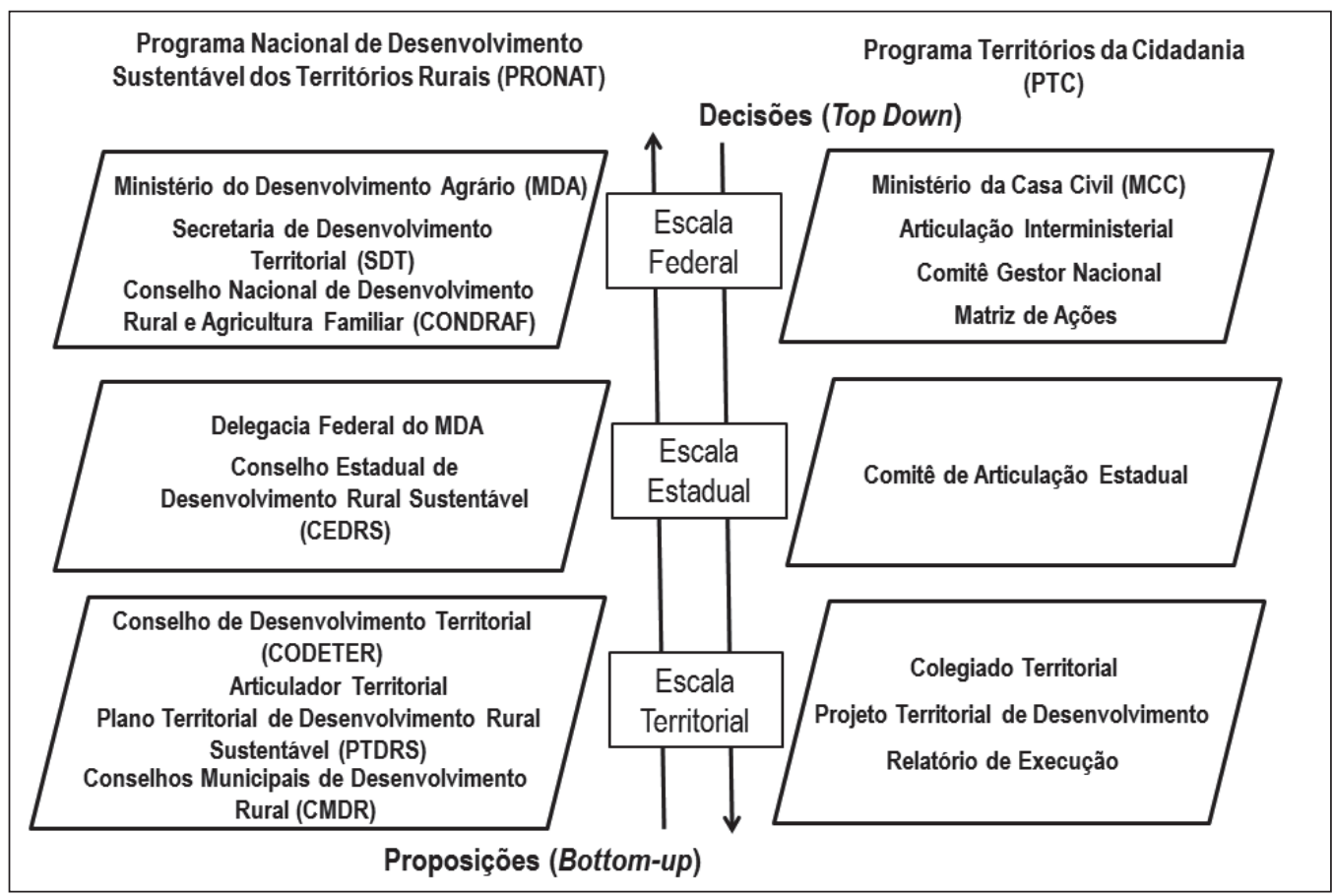

Fonte: Adaptada a partir de Caldas e Moreira (2013).

Desse contexto, a presente investigação identificou os alcances e limites do Pronat e do PTC no território Vale do Ribeira em São Paulo. Desenvolveu-se um estudo de caso descritivo-qualitativo (Yin, 2001), com visitas de campo realizadas entre agosto de 2012 e abril de 2014. Acompanhou-se por observação direta 17 momentos de reuniões no colegiado territorial, assembleias de cooperativas, feiras agroecológicas, eventos socioambientais e conferências regionais. Foram realizadas 13 entrevistas semiestruturadas e abertas com gestores públicos, líderes de associações, representantes de sindicatos e agricultores familiares. As análises documentais e de contexto complementaram o quadro empírico triangulado e interpretado à luz da abordagem territorial do desenvolvimento e do campo das políticas públicas.

Como será demonstrado nas próximas linhas, o estudo ocorreu em meio a uma fase de fragilidade das políticas de desenvolvimento territorial em nível local e nacional. Dessa forma, enfatizou-se a compreensão à perspectiva processual das ações territorializadas para dialogar com a literatura na busca de padrões e pontos em comuns dessas políticas. O artigo está organizado em quatro seções além desta introdução: uma breve descrição do território; as evidências do Pronat e do PTC; finalizando pelas conclusões e recomendações de pesquisa para o Vale do Ribeira. 


\section{O Vale do Ribeira}

Figura 3

Território da Cidadania Vale do Ribeira

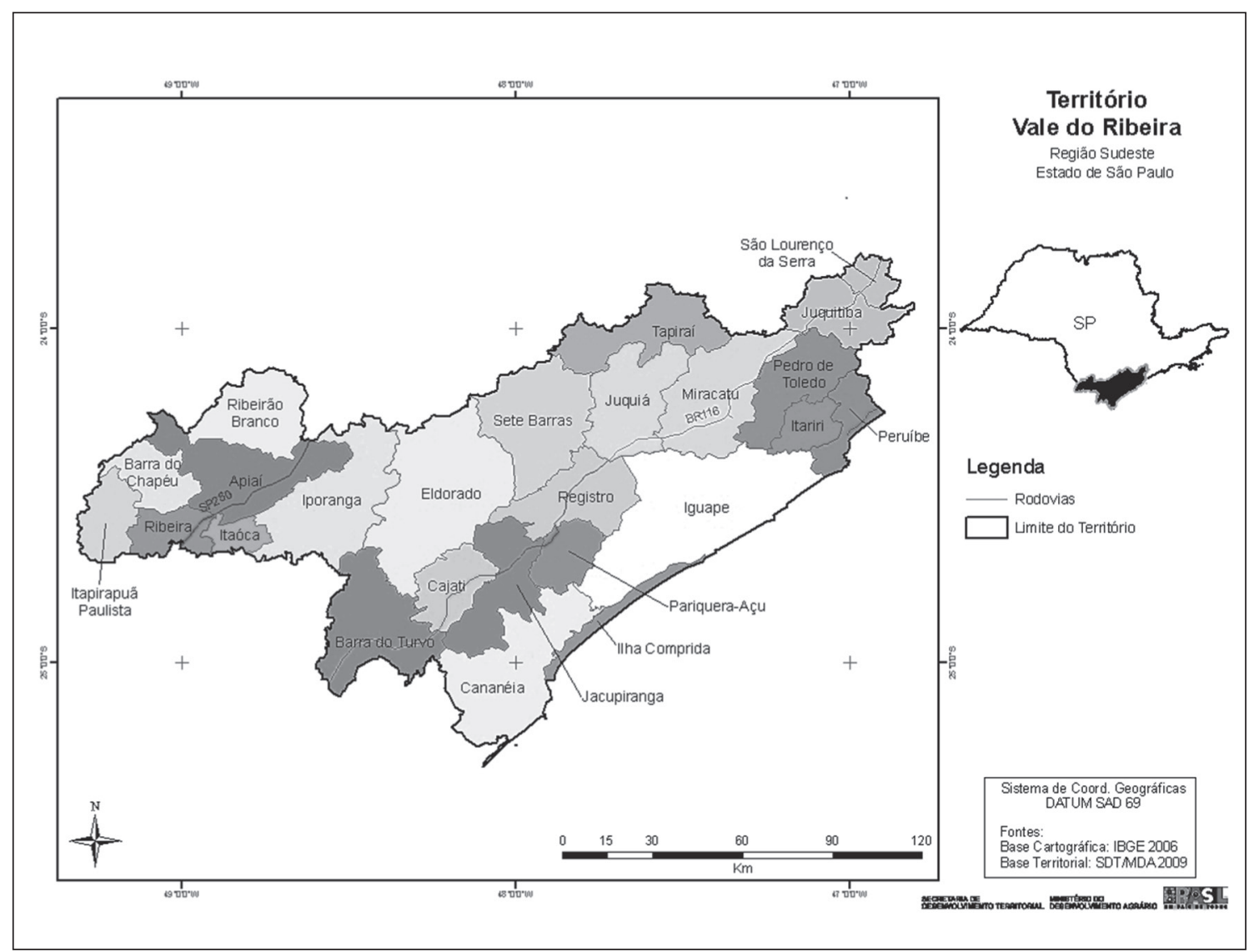

Fonte: Brasil (2010).

O território resguarda o maior contínuo de Mata Atlântica do Brasil e ampla complexidade sociocultural. Está localizado entre metrópoles de grande importância (São Paulo, Campinas, Santos, Sorocaba e Curitiba), possui 25 municípios totalizando aproximadamente 450 mil habitantes e ocupa cerca de 7\% da área do estado de São Paulo. Historicamente, o Vale do Ribeira desenvolveu-se com o ciclo escravista do ouro e do arroz, passando pelas culturas do chá e da banana na fase da colonização nipônica, incrementado pela diversificação das atividades econômicas nos últimos anos (Brasil, 2010). Durante o século passado, a região recebeu inúmeras iniciativas estatais de desenvolvimento que, em grande medida, não alcançaram suas pretensões, ao contrário, muitas vezes serviram ao clientelismo e ao acirramento dos conflitos fundiários e socioambientais (Idesc, 2006). 
Na década de 1990, houve um vácuo de ação estatal regional, o qual foi retomado com a elaboração de planos participativos de desenvolvimento, com destaque para o Programa de Fortalecimento das Vocações das Comunidades do Vale do Ribeira - Agenda Rural - elaborado em 2001 (Idesc, 2006). Entre os pontos positivos desse momento, há o surgimento de inúmeras entidades sociais endógenas (Coelho et al., 2005; Coelho e Favareto, 2008), em resposta aos conflitos socioambientais e para mobilização e reivindicação de políticas sociais executadas via União desde o início de 1990 (Abramovay e Favareto, 2010). ${ }^{2}$ Esse contexto de efervescência político-social local converge com o surgimento das políticas territoriais.

\section{O Projeto Vale do Ribeira Sustentável}

No Vale do Ribeira a política territorial foi configurada com um caráter intersetorial, integrando o Ministério do Desenvolvimento Social e Combate à Fome (MDS) - o qual já atuava no território implementando o Programa Fome Zero (PFZ) desde 2003 -, o Ministério do Meio Ambiente (MMA) e o MDA. Suas ações eram concertadas no Consórcio de Segurança Alimentar e Desenvolvimento Local do Vale do Ribeira (Consad/VR), estruturado numa composição de 150 representantes, com distribuição de 2/3 das cadeiras reservadas às organizações da sociedade civil e $1 / 3$ para o poder público (Favareto e Schroder, 2007).

Em 2004, o Consad/VR deliberou que uma ONG endógena, o Instituto para o Desenvolvimento Sustentável e Cidadania do Vale do Ribeira (Idesc), seria a entidade facilitadora da articulação interministerial no território. Em 2005 firma-se uma parceria entre o MMA e o Idesc para mobilizar R\$ 750.000,00 junto ao Fundo Nacional do Meio Ambiente (FNMA), ${ }^{3}$ e para operacionalizar o PTDRS articulado à Agenda 21 local com o apoio da assessora territorial do SDT/MDA, contratada no mesmo ano. O denominado Projeto Vale do Ribeira Sustentável (PVRS), elaborado "através de uma metodologia indubitavelmente competente e cuidadosa", segundo Coelho e colaboradores (2005:27), foi proposto num cronograma de 24 meses para ser executado por uma equipe composta por cinco coordenadores gerais, cinco técnicos e 12 mobilizadores sub-regionais.

\footnotetext{
${ }^{2}$ Nas palavras dos autores (Abramovay e Favareto, 2010:41-2), “As áreas rurais apresentaram resultados socioeconômicos bem mais edificantes que os obtidos nas regiões metropolitanas durante a década de 1990 e tudo indica que as transferências de renda tiveram aí um papel decisivo".

${ }^{3}$ Ministério do Meio Ambiente. Termo de Referência FNMA no $03 / 2004$ — Elaboração e apoio a implementação de um Plano de Desenvolvimento Territorial para o Vale do Ribeira.
} 
Figura 4

Organograma do PVRS

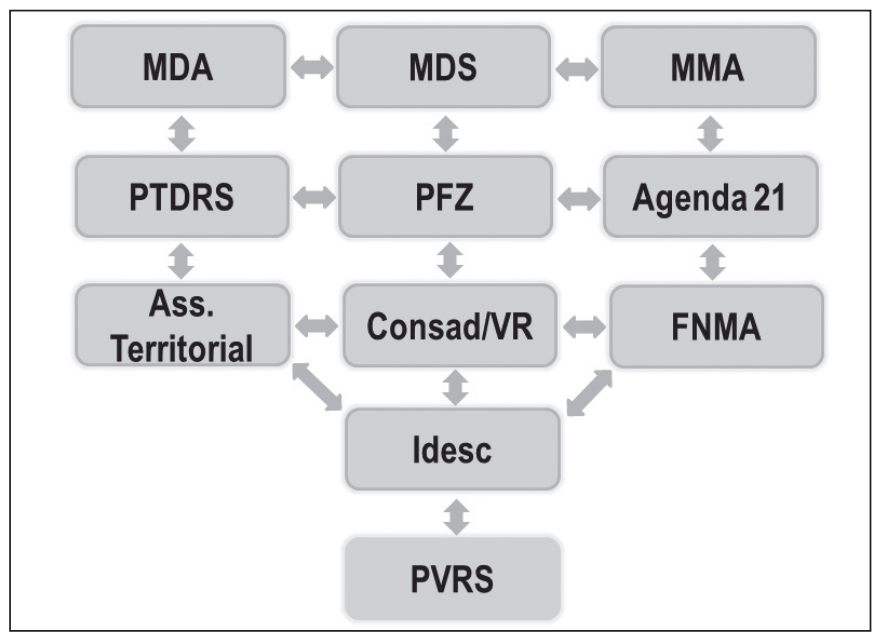

Fonte: Elaborada a partir de Idesc $(2006,2007)$ e Favareto e Schroder (2007).

Na fase de mobilização houve ampla divulgação do projeto na mídia local. Em relação às ações, elas se dividiam entre a assessoria ao funcionamento do Consad/VR, a capacitação popular para a elaboração de projetos, a construção participativa do plano territorial e a articulação deste com os poderes públicos locais. O conjunto de atividades culminou na elaboração das diretrizes do PVRS e na sua consequente aprovação junto à I Conferência Regional de Desenvolvimento Sustentável do Vale do Ribeira, realizada em 2006 (Idesc, 2006). Entre 2006 e 2007, o Idesc apoiou ações junto ao Programa de Apoio à Infraestrutura em Territórios Rurais (Proinf/MDA) e ao PFZ/MDS, além de criar dois editais de seleção de pequenos projetos socioambientais comunitários, ressaltando que esses editais buscavam atender a diversidade de atores e de propostas que iam além do escopo produtivo da agricultura familiar (tabela 1 ).

Tabela 1

Entidades proponentes, municípios, valores e projetos aprovados entre 2006 e 2007*

\begin{tabular}{|lllcl}
\hline $\begin{array}{l}\text { ASA - Associação Serrana } \\
\text { Ambientalista }\end{array}$ & Iporanga (SP) & $\begin{array}{l}\text { Educação Ambiental na Região do Alto Vale do } \\
\text { Ribeira, junto às Escolas e Integração Regional no }\end{array}$ & $9.990,50$ \\
& Desenvolvimento do Ecoturismo & \\
Associação dos Moradores do & Cajati (SP) & $\begin{array}{l}\text { Projeto de reflorestamento de áreas degradadas com } \\
\text { mairro Conchas }\end{array}$ & $\begin{array}{l}\text { mudas de árvores nativas e desenvolvimento de } \\
\text { atividades socioambientais }\end{array}$ & $8.960,50$ \\
IPeC - Instituto de Pesquisas & Cananeia (SP) & $\begin{array}{l}\text { Em cena... Ação! Educomunicação para construção da } \\
\text { agenda 21 no município de Cananeia }\end{array}$ & $9.898,00$ \\
& & &
\end{tabular}

Continua 


\begin{tabular}{|c|c|c|c|}
\hline $\begin{array}{l}\text { Associação dos Quilombos dos } \\
\text { Bairros Ribeirão Grande e Terra } \\
\text { Seca }\end{array}$ & $\begin{array}{l}\text { Barra do Turvo } \\
\text { (SP) }\end{array}$ & $\begin{array}{l}\text { Fortalecendo as famílias agricultores Quilombolas } \\
\text { no processo de reconhecimento de seus direitos e } \\
\text { construção de identidade cultural }\end{array}$ & $10.000,00$ \\
\hline $\begin{array}{l}\text { Associação dos Remanescentes } \\
\text { do Quilombo do Bairro João Surá }\end{array}$ & Adrianópolis (PR) & Projeto "Arrumando o Terrero" & $9.747,00$ \\
\hline $\begin{array}{l}\text { Cooperafloresta - Associação } \\
\text { dos agricultores Agroflorestais da } \\
\text { Barra do Turvo e Adrianópolis }\end{array}$ & $\begin{array}{l}\text { Barra do Turvo } \\
\text { (SP) }\end{array}$ & $\begin{array}{l}\text { Populações Tradicionais Gerando Renda a partir da } \\
\text { Recuperação Ambiental da Biodiversidade }\end{array}$ & $9.240,00$ \\
\hline $\begin{array}{l}\text { AABM - Associação Amigos dos } \\
\text { Bairros de Miracatu }\end{array}$ & Miracatu (SP) & $\begin{array}{l}\text { Projeto "Miracatu Um Novo Destino" - ecoturismo e } \\
\text { esportes de aventura }\end{array}$ & $9.920,00$ \\
\hline $\begin{array}{l}\text { Associação de Artesãos e } \\
\text { Produtores Caseiros de Iguape }\end{array}$ & Iguape (SP) & $\begin{array}{l}\text { Projeto "Unindo Forças" - cursos sobre associativismo } \\
\text { e liderança e motivação }\end{array}$ & $6.395,00$ \\
\hline $\begin{array}{l}\text { Amair - Associação de Monitores } \\
\text { Ambientais de Iporanga e Região }\end{array}$ & Iporanga (SP) & $\begin{array}{l}\text { Projeto "Escola no Parque" - realizar atividades de } \\
\text { Educação Ambiental e elaboração da Agenda } 21 \\
\text { Escolar }\end{array}$ & $10.000,00$ \\
\hline $\begin{array}{l}\text { Água - Associação de Economia } \\
\text { Solidária e Desenvolvimento do } \\
\text { Bairro Guapiruvu }\end{array}$ & Sete Barras (SP) & Projeto "Juceará G-30 - Manejo de Juçara" & $8.870,00$ \\
\hline $\begin{array}{l}\text { AMPRTB - Associação dos } \\
\text { Moradores e Produtores Rurais } \\
\text { de Três Barras }\end{array}$ & Cerro Azul (PR) & Projeto "Educar para Preservar" & $7.998,00$ \\
\hline $\begin{array}{l}\text { APL - Associação dos Produtores } \\
\text { de Leite do Alto Ribeira }\end{array}$ & Adrianópolis (PR) & $\begin{array}{l}\text { Projeto "Viveiro Comunitário" - implantação e } \\
\text { utilização de um viveiro para produção de alimentos, } \\
\text { florestamento e reflorestamento }\end{array}$ & $9.700,00$ \\
\hline $\begin{array}{l}\text { Aovale - Associação dos } \\
\text { Produtores Orgânicos do Vale do } \\
\text { Ribeira }\end{array}$ & Registro (SP) & $\begin{array}{l}\text { "Programa Portal Orgânico" - consolidar a } \\
\text { sustentabilidade econômica aos associados da Aovale }\end{array}$ & $8.070,00$ \\
\hline $\begin{array}{l}\text { Associação dos Remanescentes } \\
\text { de Quilombo do Bairro André } \\
\text { Lopes }\end{array}$ & Eldorado (SP) & $\begin{array}{l}\text { Projeto "Conservação de Espécie do Palmito Juçara } \\
\text { em Extinção para Fins de Geração de Renda a Médio } \\
\text { e Longo Prazo no Quilombo André Lopes" }\end{array}$ & $9.996,00$ \\
\hline $\begin{array}{l}\text { Sintravale - Associação dos } \\
\text { Trabalhadores da Agricultura do } \\
\text { Vale do Ribeira e Litoral Sul }\end{array}$ & $\begin{array}{l}\text { Barra do Turvo } \\
\text { (SP) }\end{array}$ & $\begin{array}{l}\text { Projeto "Educação Ambiental - Capacitação em } \\
\text { Associativismo" }\end{array}$ & $7.830,00$ \\
\hline $\begin{array}{l}\text { Areca - Associação Rede } \\
\text { Cananeia }\end{array}$ & Cananeia (SP) & $\begin{array}{l}\text { Projeto "Consolidação da Feira da Agricultura Familiar } \\
\text { em Cananeia" }\end{array}$ & $9.980,00$ \\
\hline $\begin{array}{l}\text { Asstraf - Associação Sindical } \\
\text { dos Trabalhadores da Agricultura } \\
\text { Familiar }\end{array}$ & Cerro Azul (PR) & Projeto "Desenvolvimento Agroflorestal em Cerro Azul" & $9.963,00$ \\
\hline $\begin{array}{l}\text { Centro de Estudos Ecológicos + } \\
\text { Gaia Ambiental }\end{array}$ & Cananeia (SP) & $\begin{array}{l}\text { Projeto "Viveiros Agroflorestais da Agricultura Familiar } \\
\text { de Cananeia" }\end{array}$ & $9.761,00$ \\
\hline
\end{tabular}




\begin{tabular}{|c|c|c|c|}
\hline $\begin{array}{l}\text { Colônia de Pescadores Z-7 "Veiga } \\
\text { Miranda" }\end{array}$ & Iguape (SP) & Projeto "Campanha Pesca Consciente" & $8.771,00$ \\
\hline $\begin{array}{l}\text { Fepar - Federação Paranaense } \\
\text { das Associações dos Produtores } \\
\text { Rurais }\end{array}$ & $\begin{array}{l}\text { Itaperuçu/Rio } \\
\text { Branco do Sul } \\
\text { (PR) }\end{array}$ & Projeto "Tempo de Cuidar para Semear" & $8.240,00$ \\
\hline $\begin{array}{l}\text { STR - Sindicato dos } \\
\text { Trabalhadores Rurais de Cajati }\end{array}$ & Cajati (SP) & $\begin{array}{l}\text { Projeto "Implantação de Unidades de Experiência } \\
\text { Piloto do Sistema de Fossas Sépticas e conversão da } \\
\text { coleta sanitária em Adubo Orgânico" }\end{array}$ & $10.000,00$ \\
\hline $\begin{array}{l}\text { Apoarp - Associação dos } \\
\text { Produtores Orgânicos } \\
\text { Autossustentáveis do Bairro } \\
\text { Ribeirão dos Pontes }\end{array}$ & Apiaí (SP) & $\begin{array}{l}\text { "Projeto de Implantação de Fosse Séptica Biodigestora } \\
\text { no Bairro Ribeirão dos Pontes" }\end{array}$ & $9.936,68$ \\
\hline
\end{tabular}

Fonte: Idesc (2007). Elaborada pelo autor.

*No início do PVRS foi realizada uma parceria com os municípios do Fórum do Paraná no intuito de utilizar a escala da bacia hidrográfica como unidade de planejamento. Porém, essa aproximação durou até 2007.

Ao todo, 22 propostas foram aprovadas sob um valor total de $\mathrm{R} \$ 203.567,00$. Os projetos recusados eram arquivados num banco de dados para serem avaliados e readequados. Houve um acompanhamento contínuo da execução das ações e da prestação de contas. Os esforços coletivos locais para alcançar uma "lógica territorial e de projetos" (Beduschi Filho e Abramovay, 2004:6) geraram práticas de aprendizagem social, institucional e política entre os agentes (Aquino e Silva, 2015; Caldas e Moreira, 2013; Carvalho e David, 2011; Freitas, Freitas e Dias, 2012; Ribeiro, Andion e Burigo, 2015).

Os atores entrevistados neste estudo são enfáticos em apontar as virtudes do PVRS, tanto em relação ao fortalecimento das comunidades de agricultores familiares, como na transformação do colegiado num espaço legítimo de cogestão. Bonnal e Maluf (2009:238) citam o Consad/VR como um dos "exemplos de relações e [...] articulação de três programas de diferentes ministérios". Onaur Ruano, na época representante do MDS, afirmou que o consórcio era considerado "modelo classe A" e a experiência o tornava "uma referência para todo o Brasil" (Idesc, 2007:54).

Entretanto, mesmo elaborado, o PVRS não foi executado por não ter ocorrido a renovação da parceria entre o Idesc e o MMA, somada à saída da ONG do projeto em 2008. O motivo dessa saída está relacionado com o pleito eleitoral de 2007 em Registro, principal município do território, o qual levou à dissolução da metade da equipe coordenadora, que decidiu concorrer às eleições pelo PT. Tais fatos levaram a um acirramento do conflito político entre PSDB, PMDB e PT (Coelho e Favareto, 2008) em torno de um suposto uso político-ideológico do Consad/VR.

Observam-se tanto a fragilidade apresentada por instituições como ONGs para operacionalizar uma política de alcance territorial como o uso político da posição de mobilizador social (Sabourin, 2015), que pode resultar na perda de lideranças locais e na consequente desmobilização popular. Adicionam-se os achados de Favareto e Schroder (2007), que elucidaram os limites setoriais da execução do Pronat no Vale do Ribeira. 
Os representantes municipais atuavam de forma simbólica, sem comprometerem os repasses de fundos municipais ou disponibilizarem técnicos para apoio à gestão do Consad/VR. Se antes os prefeitos centralizavam o poder das decisões por meio dos conselhos municipais, no Pronat esse quadro foi relativamente alterado, e, como consequência, surgiram resistências destes em executar políticas junto às entidades sociais (Delgado e Grisa, 2014; Sabourin, 2015).

As ações operacionalizadas no Consad/VR prescindiam da participação das secretarias e órgãos públicos estaduais. Essas instituições possuem um papel estrutural para resolução das questões relacionadas com os conflitos socioambientais e as posses irregulares, onde aproximadamente $40 \%$ das propriedades do Vale não possuem situação dominial regularizada (Idesc, 2006). A desarticulação entre a União e os governos estaduais (Aquino e Silva, 2015; Karam, 2012; Sabourin, 2012) ocorreu de forma explícita no caso do estado de São Paulo (Caldas e Moreira, 2013; Coelho et al., 2005). É nesse contexto que o PTC incide no território Vale do Ribeira.

\section{Do PVRS ao Programa Territórios da Cidadania: continuidades e descaminhos}

O PTC foi incorporado ao Consad/VR no intuito de aumentar a robustez das ações desenvolvidas no PVRS. O marketing político do novo programa incentivou a participação de técnicos locais no seu início em decorrência das expectativas de executar um expressivo aumento de recursos. Se no Pronat as verbas repassadas giravam em torno de $\mathrm{R} \$ 150.000,00$ a $\mathrm{R} \$ 2.000 .000,00 /$ ano (Coelho e Favareto, 2008:20), os valores repassados no PTC chegariam a aproximadamente R\$ 524 milhões entre os anos de 2008, 2009, 2010 e 2013.

Porém, as ações territorializadas foram executadas como cesta de políticas dispersas, que na realidade já eram implementadas antes do surgimento do PTC. As verbas repassadas pelas Matrizes de Ações ao território compunham em sua maioria propostas do MDS e do MDA, praticamente inexistindo verbas de outros ministérios. As ações, operacionalizadas diretamente pelas prefeituras e sem intermediação ou controle social por parte do Consad/VR, são fragmentadas e não alcançam todos os municípios do território. Ademais, a alteração na proporção das cadeiras disponíveis à sociedade civil, que passou de $2 / 3$ para $50 \%$, contribuiu para a desmobilização desse colegiado.

Após a saída do Idesc, as funções da assessora territorial ficaram sobrecarregadas, as quais se agravaram quando o MDA não repassou as verbas às entidades contratantes entre 2009 e 2013. Com tal impasse, a assessora foi obrigada a dividir-se entre atuar no Consad/ VR como voluntária e em "bicos" nas ONGs regionais. Os relatos das atividades do colegiado realizadas nesse período não foram avaliados ou disponibilizados no sítio eletrônico do PTC pelo SDT. Nesse contexto, surgiram casos de entidades resistentes em manter parcerias com o MDA, tornando precária a situação da assessora e restringindo seu papel à militância corporativa com dependência financeira das organizações locais (Caldas e Moreira, 2013; Delgado e Grisa, 2014; Sabourin 2015). Karam (2012:43) aponta que "o Territórios da Cidadania não 
possui estrutura burocrática, fundos contábeis ou sequer orçamento próprio sob sua gestão, a despeito do montante de recursos com os quais lida".

Em 2012 houve uma tentativa de reanimação do Consad/VR motivada por suas eleições internas, a qual malogrou resultado de um impedimento jurídico, cujo responsável foi o presidente à frente da gestão anterior que não registrou os quadros eleitos no Cartório Eleitoral. Como consequência, o Tribunal de Contas do Estado São Paulo determinou a interrupção das atividades do colegiado. Ao contrário dos casos onde a ausência de estrutura jurídica emperrara a gestão territorial (Aquino e Silva, 2015; Caldas e Moreira, 2013; Sabourin, 2015), no Vale do Ribeira foi o arranjo de uma associação civil sem fins lucrativos que causou seu engessamento. Uma das soluções colocadas na época seria a transformação do Consad/VR num consórcio público ou a articulação deste com o Consórcio de Desenvolvimento Intermunicipal do Vale do Ribeira (Codivar), criado em 1989 pelo governo estadual. Entretanto, tais propostas sofreram forte resistência dos atores políticos locais, levando à rejeição das mesmas.

Devido aos inúmeros imbróglios jurídicos, o Consad/VR foi fechado em junho de 2014 para o surgimento do Codeter/VR em maio de 2015, o qual se integrou à cooperação técnica entre o SDT/MDA, o Conselho Nacional de Desenvolvimento Científico e Tecnológico do Ministério da Ciência, Tecnologia e Inovação (CNPq/MCTI) e a Diretoria de Políticas para as Mulheres Rurais (DPMR/MDA). Essa articulação resultou na implantação de um Núcleo de Extensão em Desenvolvimento Territorial (Nedet/MDA), que visa assessorar as ações no território, além de realizar assistência técnica, capacitação e extensão universitária (Sabourin, 2015). No Vale do Ribeira, a instituição responsável pelo núcleo é a Universidade Estadual Paulista (Unesp) de Presidente Prudente. ${ }^{4}$ O novo ciclo de gestão foi iniciado em $2013 \mathrm{em}$ escala nacional, na tentativa de reverter a crise político-financeira dos programas territoriais deflagrada em 2011 (Delgado e Grisa, 2014; Zimmermann et al., 2014).

Segundo Abramovay, Magalhães e Schroder (2010:285), os colegiados territoriais "não exprimem o conjunto das forças vivas do território que se organizam e não influem sobre as decisões quanto ao uso de seus recursos". Portanto, há um processo de "ilusão" dos mecanismos de participação (Caldas e Moreira, 2013:55), de fragilidade inerente à gestão social dos territórios (Oliveira et al., 2014), o não estímulo à diversidade dos atores (Souza e Amaral, 2015) e a ausência de pluralidade de interesses (Zani e Tenório, 2014) em torno desses arranjos. Adicionam-se os obstáculos estruturais referentes aos conflitos fundiários e à reforma agrária que ficaram obscurecidos durante a execução das políticas territoriais (Sant'Anna Porto, 2015).

Fatores como a inexistência de intersetorialidade entre ministérios, concomitante à fragmentação e à sobreposição das diferentes ações de enfoque regional/territorial, os quais competem por recursos e por importância, evidenciam a ausência de planejamento e da descentralização coordenada das políticas em análise (Delgado e Grisa, 2014; Goulart et al., 2010;

\footnotetext{
${ }^{4}$ Esta ação é parte do Projeto "Rede de Apoio aos Territórios da Cidadania de São Paulo: extensão e pesquisa universitária para o desenvolvimento rural”, iniciado em 2014 e coordenado pela UNESP Presidente Prudente.
} 
Karam, 2012; Paula, 2005; Sabourin, 2012, 2015). Grisa e Schneider (2014) sugerem que, apesar da emergência normativa dos territórios (Favareto, 2010), os programas abordados nessas linhas dão continuidade às políticas socioassistenciais de caráter distributivo iniciadas na década de 1990 (Abramovay e Favareto, 2010). A prioridade do governo federal à agenda social, a exemplo do Programa Brasil Sem Miséria (Zimmermann et al., 2014), e a estratégia agroexportadora de commodities ligada aos megaempreendimentos de desenvolvimento e infraestruturas, com suas graves consequências socioambientais (Ferreira et al., 2014; Vieira, 2009; Souza e Amaral, 2015), ilustra o papel secundário e compensatório promovido pelas políticas de desenvolvimento territorial no atual cenário (Sant’Anna Porto, 2015).

\section{Considerações finais}

A sistematização das experiências relativas às políticas territoriais no Vale do Ribeira possibilita observar que, por um lado, as ações do arranjo intersetorial entre o MDA, o MDS e o MMA surtiram um efeito parcial, mas de grande importância para o fortalecimento do movimento dos agricultores familiares e para a mobilização da sociedade civil organizada. Por outro lado, a tênue articulação política entre as diferentes esferas do poder público não possibilitou a implantação do plano territorial. A saída do Idesc da coordenação das ações no Consad/VR redundou na diluição do Projeto Vale do Ribeira Sustentável. Como consequência, a implementação do PTC se deu sob frágeis bases participativas, fato agravado pelo engessamento institucional do colegiado, o que gerou uma desmobilização popular generalizada. Tal resultante evidencia uma estrutura de ação pública local incompatível quando considerado seu objetivo de gestão e concertação social sob o prisma do enfoque territorial do desenvolvimento. Da perspectiva processual da política (Frey, 2000), os obstáculos referentes à não resolução de tensões partidárias regionais impedem a cooperação e os esforços planejados voltados ao desenvolvimento rural sustentável.

Num olhar mais amplo, a maioria das experiências territoriais gerou processos aquém das expectativas iniciais (Berdegué, Escobal e Bebbington, 2015). Os casos observados com saliências positivas relativas à ativação dos mecanismos de participação e concertação (Aquino e Silva, 2015; Freitas, Freitas e Dias, 2012), à elaboração de planos territoriais maduros (Ribeiro, Andion e Burigo, 2015) e à emergência e ao fortalecimento de mercados solidários de proximidade (Carvalho e David, 2011) são ilustrações que em comum resultam de um círculo virtuoso anterior de enraizamento da identidade coletiva e da construção social do desenvolvimento local. A lição extraída desta pesquisa reside no desafio do repensar as ações públicas de desenvolvimento segundo os pilares da "nova ruralidade" (Wanderley, 2000), articulados aos enfoques críticos do ecodesenvolvimento e do desenvolvimento territorial sustentável (Vieira, 2009).

Há a necessidade de estudos sobre as políticas de desenvolvimento no âmbito do governo estadual incidentes no Vale do Ribeira, cujas análises são escassas na literatura cientí- 
fica. As "forças vivas" desse território poderiam ser mobilizadas pelas leituras relacionais, tais como as redes de políticas públicas (Frey, 2000; Goulart et al., 2010), a abordagem cognitiva (Grisa e Schneider, 2014) e a teoria da reciprocidade (Sabourin, 2012).

\section{Referências}

ABRAMOVAY, Ricardo; FAVARETO, Arilson S. Contrastes territoriais dos indicadores de renda, pobreza monetária e desigualdade no Brasil na década de 1990. Ruris, Campinas, v. 4, n. 1, p. 39-83, mar. 2010.

ABRAMOVAY, Ricardo; MAGALHÃES, Reginaldo; SCHRODER, Mônica. Representatividade e inovação na governança dos processos participativos: o caso das organizações brasileiras de agricultores familiares. Sociologias, Porto Alegre, v. 12, n. 24, p. 268-306, maio/ago. 2010.

AQUINO, Janio N.; SILVA, Maria J. P. Desenvolvimento territorial e participação social em políticas públicas: o caso do Conselho Territorial do Alto Acre e Capixaba - CTAC. Revista em Gestão, Inovação e Sustentabilidade, Brasília, v. 1, n. 1, p. 170-192, dez. 2015.

BEDUSCHI FILHO, Luiz C.; ABRAMOVAY, Ricardo. Desafios para o desenvolvimento das regiões rurais. Nova Economia, Belo Horizonte, v. 14, n. 3, p. 35-70, 2004.

BERDEGUÉ, Julio A.; ESCOBAL, Javier; BEBBINGTON, Anthony. Explaining spatial diversity in Latin American rural development: structures, institutions, and coalitions. World Development, Amsterdã, v. 73, p. 129-137, set. 2015.

BONNAL, Philippe; MALUF, Renato S. Políticas de desenvolvimento territorial e multifuncionalidade da agricultura familiar no Brasil. Política \& Sociedade, Florianópolis, v. 8, n. 14, p. 211-250, abr. 2009.

BRASIL. Ministério do Desenvolvimento Agrário. MDA. Plano territorial de desenvolvimento rural sustentável território Vale do Ribeira (SP). Elaborado em 2006 e atualizado em 2011. MDA/Plural, nov. 2010.

CALDAS, Eduardo L.; MOREIRA, Ivaldo. Políticas de desenvolvimento territorial e intermunicipalidade no Brasil: complementaridades e tensões. Sustentabilidade em Debate, Brasília, v. 4, n. 2, p. 41-61, jul./dez. 2013.

CARVALHO, Ananda; DAVID, Cesar. Possibilidades e limites do Programa Territórios da Cidadania a partir da sua realização no território Região Central e no município de Santa Maria/RS. Agrária, São Paulo, n. 14, p. 55-77, 2011.

COELHO, Vera S. P.; FAVARETO, Arilson S. Dilemas da participação e desenvolvimento territorial. Revista de Desenvolvimento Econômico, Salvador, v. 10, n. 18, p. 15-26, dez. 2008.

COELHO, Vera S. P. et al. As regras do jogo e o jogo das regras - movimentos sociais, governança ambiental e desenvolvimento territorial no Vale do Ribeira (Brasil). Rimisp, Santiago, 2005. Manuscrito. 
DELGADO, Nelson G.; GRISA, Catia. Políticas de desenvolvimento territorial e pobreza rural no Brasil: análise das institucionalidades e da governança. Estudos, Sociedade e Agricultura, Rio de Janeiro, v. 22, n. 1, p. 132-163, 2014.

FAVARETO, Arilson S. Abordagem territorial do desenvolvimento rural - mudança institucional ou "inovação por adição"? Estudos Avançados, São Paulo, v. 24, n. 68, p. 299-219, 2010.

FAVARETO, Arilson S.; SCHRODER, Mônica. Do território como "ator" ao território como "campo": uma análise da introdução da abordagem territorial na política de desenvolvimento rural no Brasil. In: CONGRESSO DA SOCIEDADE BRASILEIRA DE ECONOMIA, ADMINISTRAÇÃO E SOCIOLOGIA RURAL — SOBER, XVL, julho de 2007, UEL, Londrina.

FERREIRA, Joice N. et al. Brazil's environmental leadership at risk. Science, Nova York, v. 346, n. 6210, p. 706-707, nov. 2014.

FREITAS, Alan F.; FREITAS, Alair F.; DIAS, Marcelo M. O colegiado de desenvolvimento territorial e a gestão social de políticas públicas: o caso do Território Serra do Brigadeiro, Minas Gerais. Rev. Adm. Pública, Rio de Janeiro, v. 46, n. 5, 1201-1223, set./out. 2012.

FREY, Klaus. Políticas públicas: um debate conceitual e reflexões referentes à prática da análise de políticas públicas no Brasil. Planejamento e Políticas Públicas, Brasília, n. 21, p. 211-259, jun. 2000.

GOULART, Sueli et al. Articulações em rede e acontecimentos no território: subsídios teóricos para a formação de políticas públicas para o desenvolvimento. Cad. EBAPE.BR, Rio de Janeiro, v. 8, n. 3 , art. 1, p. 388-403, set. 2010.

GRISA, Catia; SCHNEIDER, Sergio. Três gerações de políticas públicas para a agricultura familiar e formas de interação entre sociedade e Estado no Brasil. Revista de Economia e Sociologia Rural, Piracicaba, v. 52, n. Supl. 1, p. S125-S146, 2014.

GURZA LAVALLE, Adrian; ISUNZA, Ernesto V. A trama da crítica democrática: da participação à representação e à accountability. Lua Nova, São Paulo, n. 84, p. 95-139, 2011.

IDESC. Instituto para o Desenvolvimento Sustentável e Cidadania no Vale do Ribeira. Plano de desenvolvimento territorial sustentável do Vale do Ribeira. 2006. Disponível em: <www.idesc.org. br/planos_vale.asp>. Acesso em: 15 nov. 2014.

IDESC. Instituto para o Desenvolvimento Sustentável e Cidadania no Vale do Ribeira. Relatórios do PVRS. 2007. Disponível em: <www.idesc.org.br/relatorio.asp>. Acesso em: 15 nov. 2014.

KARAM, Ricardo A. S. A questão regional brasileira no século XXI: um olhar sobre o dissenso. Informações Sociais, Brasília, v. 6, n. 1, p, 33-51, jul./dez. 2012.

OLIVEIRA, Carlos D. S. et al. Gestão social e institucional em territórios rurais: contribuições a partir do Território Zona Sul do Rio Grande do Sul. Revista Interdisciplinar de Gestão Social, Salvador , v. 3, n. 2, p. 59-78, mai./ago. 2014.

PAULA, Ana P. P. Administração pública brasileira entre o gerencialismo e a gestão social. Revista de Administração de Empresas, Rio de Janeiro, v. 45, n. 1, p. 36-49, jan./mar. 2005. 
RIBEIRO, Alexandre C.; ANDION, Carolina; BURIGO, Fábio. Ação coletiva e coprodução para o desenvolvimento rural: um estudo de caso no Colegiado de Desenvolvimento Territorial da Serra Catarinense. Rev. Adm. Pública, Rio de Janeiro, v. 49, n. 1, p. 119-140, jan./fev. 2015.

SABOURIN, Eric. Evolução da política federal de desenvolvimento territorial no Brasil. Novos Cadernos Naea, Belém, v. 18, n. 1, p. 123-143, jan./jul. 2015.

SABOURIN, Eric. Reciprocidade e análise de políticas públicas rurais no Brasil. Ruris, Campinas, v. 6, n. 2, p. 53-90, set. 2012.

SANT'ANNA PORTO, José R. Conexões, apropriações e exclusões no discurso do desenvolvimento territorial no Brasil. Novos Cadernos Naea, Belém, v. 18, n. 1, p. 145-168, jan./jul. 2015.

SOUZA, Gabriela C.; AMARAL, Cleomara N. Política territorial e os agricultores tradicionais da baixada cuiabana, Mato Grosso. Guaju, Matinhos, v. 1, n. 1, p. 64-89, jan./jun. 2015.

VIEIRA, Paulo F. Políticas ambientais no Brasil: do preservacionismo ao desenvolvimento territorial sustentável. Política \& Sociedade, Florianópolis, v. 8, n. 14, p. 27-75, abr. 2009.

WANDERLEY, Maria N. B. A emergência de uma nova ruralidade nas sociedades modernas avançadas - o "rural" como espaço singular e ator coletivo. Estudos Sociedade e Agricultura, Rio de Janeiro, n. 15, p. 87-145, out. 2000.

YIN, Robert K. Estudo de caso: planejamento e método. 2. ed. Porto Alegre: Bookman. 2001.

ZANI, Felipe B.; TENÓRIO, Fernando G. Gestão social do desenvolvimento: o desafio da articulação de atores sociais no Programa Territórios da Cidadania Norte-RJ. Organizações \& Sociedade, Salvador, v. 21, n. 68, p. 97-118, jan./mar. 2014.

ZIMMERMANN, Silvia A. et al. Desenvolvimento territorial e políticas de enfrentamento da pobreza rural no Brasil. Campo-Território: Revista de Geografia Agrária, Uberlândia, v. 9, n. 17, p. 540-573, abr. 2014.

Joaquim Alves da Silva Jr. é gestor ambiental pela Escola de Artes, Ciências e Humanidades (EACH/USP) e mestre em ciências pelo Programa de Pós-Graduação em Ciência Ambiental (Procam) do Instituto de Energia e Ambiente (IEE) da Universidade de São Paulo (USP). E-mail: joaquimasjr@gmail.com. 